\title{
Invasive adenocarcinoma with bronchoalveolar features: A population-based evaluation of the extent of resection in bronchoalveolar cell carcinoma
}

\author{
Bryan A. Whitson, MD, PhD, Shawn S. Groth, MD, MS, Rafael S. Andrade, MD, Mohi O. Mitiek, MD,
} Michael A. Maddaus, MD, and Jonathan D'Cunha, MD, PhD

Objective: We used a population-based data set to assess the association between the extent of pulmonary re-
section for bronchoalveolar carcinoma and survival. The reports thus far have been limited to small, institutional series.

\begin{abstract}
Methods: Using the Surveillance, Epidemiology, and End Results database (1988-2007), we identified patients with bronchoalveolar carcinoma who had undergone wedge resection, segmentectomy, or lobectomy. The bronchoalveolar carcinoma histologic findings were mucinous, nonmucinous, mixed, not otherwise specified, and alveolar carcinoma. To adjust for potential confounders, we used a Cox proportional hazards regression model.

Results: A total of 6810 patients met the inclusion criteria. Compared with the sublobar resections (wedge resections and segmentectomies), lobectomy conferred superior 5-year overall (59.5\% vs $43.9 \%)$ and cancerspecific $(67.1 \%$ vs $53.1 \%)$ survival $(P<.0001)$. After adjusting for potential confounding patient and tumor characteristics, we found that patients who underwent an anatomic resection had significantly better overall (segmentectomy: hazard ratio, $0.59 ; 95 \%$ confidence interval, $0.43-0.81$; lobectomy: hazard ratio, $0.50 ; 95 \%$ confidence interval, 0.44-0.57) and cancer-specific (segmentectomy: hazard ratio, $0.51 ; 95 \%$ confidence interval, 0.34-0.75; lobectomy: hazard ratio, 0.46; 95\% confidence interval, 0.40-0.53) survival compared with patients who underwent wedge resection. Additionally, gender, race, tumor size, and degree of tumor de-differentiation were negative prognostic factors. Our results were unchanged when we limited our analysis to early-stage disease.
\end{abstract}

Conclusions: Using a population-based data set, we found that anatomic resections for bronchoalveolar carcinoma conferred superior overall and cancer-specific survival rates compared with wedge resection. Bronchoalveolar carcinoma's propensity for intraparenchymal spread might be the underlying biologic basis of our observation of improved survival after anatomic resection. (J Thorac Cardiovasc Surg 2012;143:591-600)

Earn CME credits at

http://cme.ctsnetjournals.org

Supplemental material is available online.

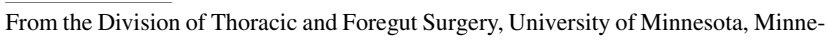
apolis, Minn.

Disclosures: Authors have nothing to disclose with regard to commercial support. This report was a Paul C. Samson Resident Manuscript Competition Finalist.

Read at the 37th Annual Meeting of The Western Thoracic Surgical Association, Colorado Springs, Colorado, June 22-25, 2011.

Received for publication June 21, 2011; revisions received Sept 24, 2011; accepted for publication Oct 5, 2011; available ahead of print Dec 19, 2011.

Address for reprints: Jonathan D'Cunha, MD, PhD, Division of Thoracic and Foregut Surgery, Department of Surgery, University of Minnesota, MMC 207, 420 Delaware Street Southeast, Minneapolis, MN 55455 (E-mail: jdcunha@umn.edu). $0022-5223 / \$ 36.00$

Copyright (c) 2012 by The American Association for Thoracic Surgery doi:10.1016/j.jtcvs.2011.10.088
In the surgical treatment of non-small cell lung cancer (NSCLC), there is an evolving interest and emphasis in parenchymal-sparing operations for appropriately sized tumors. ${ }^{1-3}$ Thus far, data on the association between the extent of resection and survival have been limited to singleinstitutional series, ${ }^{4-7}$ a randomized trial of all NSCLC histologic findings, ${ }^{8}$ and analyses of administrative data sets limited to patients with the most common NSCLC histologic types (ie, adenocarcinoma and squamous cell carcinoma). ${ }^{9}$

Interest in bronchoalveolar cell carcinoma (BAC) as a separate histologic type or subclass of adenocarcinoma is evolving. ${ }^{10-12}$ Historically, radiographic findings of infiltrative or mass-like patterns could correlate with mucinous or nonmucinous histologic findings. ${ }^{13}$ In the spring of 2011, the current understanding of BAC has brought into the nomenclature the new terms of "adenocarcinoma in situ," "minimally invasive adenocarcinoma," and "invasive adenocarcinoma." 14 How these new classifications will affect treatment will be elucidated during the upcoming years.

Traditional teaching is that a lesion with BAC histologic features undergoes wedge resection to free margins. 


\section{Abbreviations and Acronyms \\ $\mathrm{BAC}=$ bronchoalveolar cell carcinoma \\ NSCLC $=$ non-small cell lung cancer \\ PET = positron emission tomography \\ SEER = Surveillance, Epidemiology, and End Results}

Sublobar resections have also been advocated. ${ }^{15,16}$ To date, the published data on the association between the sublobar resections for BAC and survival has been limited to small series. ${ }^{17-19}$ To our knowledge, no studies have been published that have used larger data sets to compare survival after lobectomy versus sublobar resection (anatomic segmentectomy and wedge resection) for BAC. The analysis of these lesions is complicated by the dominant cellular type, the presence of pure cellular histologic features, and the extent of resection.

We hypothesized that a lobar resection would yield a superior overall and cancer-specific survival rates for BAC compared with a sublobar resection (segmentectomy and wedge resection); and that an anatomic resection (lobectomy or segmentectomy) would yield superior overall and cancer-specific survival compared with nonanatomic resection (wedge resection). To evaluate these hypotheses using population-based data, we queried the Surveillance, Epidemiology, and End Results (SEER) database.

\section{MATERIALS AND METHODS}

The SEER database, founded in 1973 by the National Cancer Institute (Bethesda, Md), is a data set that includes data from 17 cancer registries, encompassing approximately $26 \%$ of the U.S. population. We used data from the November 2009 submission, which provides data through December 31,2007 . We limited our analysis to data collected from January 1, 1988 (the year SEER began collecting American Joint Committee on Cancer staging data), through December 31, 2007. Because the SEER registries did not differentiate the types of sublobar resections (ie, wedge resections and segmentectomies) until 1998, our survival analysis comparing wedge resection, segmentectomy, and lobectomy was limited to data obtained from January 1, 1998 through December 31, 2007. Because of the negative affect of Hurricane Katrina on data collection by the Louisiana SEER registry, we excluded information obtained by that registry in 2005 . We collected information on patient factors (ie, age, race, and gender), tumor characteristics (ie, size, grade, and histologic type), treatment factors (ie, extent of resection and lymph node yield), and geographic treatment location (determined by cancer registry in which the data were collected).

For our analysis, we included patients 18 years and older who underwent either lobectomy or sublobar resection for BAC. The BAC histologic subtypes were categorized as follows: BAC not otherwise specified, alveolar, nonmucinous, mucinous, and mixed type. To eliminate the potential for confounding, mixed adenocarcinoma-BAC histologic types were excluded.

Patients with more than 1 primary tumor were excluded. Those patients with Stage IV disease were excluded. Because of the potential for confounding, we also excluded those patients who were unlikely to have received aggressive cancer treatment (ie, patients with a hospice, nursing home, autopsy, or death certificate as their only reporting source).
A previous study using SEER data found that survival after resection of NSCLC was optimized when 11 to 16 lymph nodes were examined. ${ }^{20}$ Consequently, the lymph node counts were categorized as follows: 0,1 to 10,11 to 16 , and 17 or more lymph nodes.

The data were analyzed with SAS, version 9.1 (SAS Institute, Cary, NC). For all statistical testing, we used a 2-sided significance level of .05 . For between-group comparisons, we used a chi-square test for categorical variables. The Kaplan-Meier method was used to compare the unadjusted all-cause mortality and cancer-specific mortality rates between sublobar resection and lobectomy. To adjust our survival analysis for potentially confounding patient and tumor factors, we used a Cox proportional hazards regression model. Log-log survival plots were generated after the proportional hazards assumption was tested to assess for homogeneity of the hazards ratio over time.

\section{RESULTS \\ Lobar Versus Sublobar (Segmentectomy and Wedge Resection)}

From our query of the SEER data set, we identified 6810 patients who met our inclusion criteria (Figure 1). Of these, 5532 patients underwent lobectomy and 1278 underwent sublobar resection (Table 1). Of those with sublobar resections, 768 underwent wedge resection. From our KaplanMeier analyses, we found that lobectomy was associated with significantly better overall survival and cancerspecific survival compared with sublobar resection (Figure 2). When the sublobar resections were separated into segmentectomy and wedge resection and analyzed using the Kaplan-Meier method, we observed similarly, highly significant, differences in overall and cancer-specific survival. The survival curves for the segmentectomy and lobectomy patients were essentially indistinguishable.

When we adjusted our survival analysis to account for potential confounders using a Cox proportional hazards regression model, we found that lobectomy was an independent predictor of improved all-cause and cancer-specific mortality compared with sublobar resection (Table 2). We also compared anatomic resections (lobectomy and segmentectomy) and wedge resection. Both anatomic segmentectomy and lobectomy were independently associated with improved all-cause and cancer-specific mortality compared with wedge resection. No significant difference was found in survival between the patients who underwent lobectomy and those who underwent anatomic segmentectomy (Table 3).

\section{Patient Age}

For the entire study population, the mean age was $67.3 \pm$ 10.3 years. For those who underwent wedge resection, the mean age was $67.6 \pm 11$ years. For those who underwent segmentectomy, the mean age was $69.6 \pm 10.4$ years. For those who underwent lobectomy, the mean age was 67.2 \pm 10.2 years. Most patients were elderly (Table 1). From our multivariate analysis, increasing age was associated with an increased risk of death (Tables 2 and 3). 


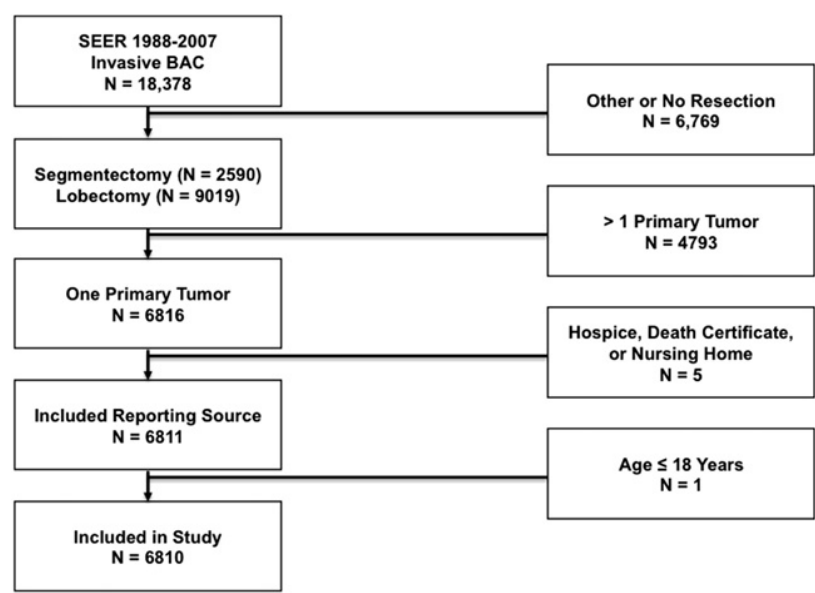

FIGURE 1. Sample inclusion and exclusion selection criteria. $B A C$, Bronchoalveolar cell carcinoma; SEER, Surveillance, Epidemiology, and End Results.

\section{Race}

In the whole study population, more than $80 \%$ were white, with the remainder black and other ethnicities (Table 1). Black race was associated with a greater risk of all-cause and cancer-specific mortality (Tables 2 and 3).

\section{Gender}

In both analyses, approximately two thirds of the patients were women (Table 1). Men had significantly greater allcause and cancer-specific mortality rates in both the lobar versus sublobar and anatomic versus nonanatomic resection analyses (Tables 2 and 3).

\section{Tumor Size}

For those patients who underwent lobectomy, the greatest proportion of tumor sizes was from 2 to $2.9 \mathrm{~cm}$ in diameter. This was followed by less than $2 \mathrm{~cm}$ to 3 to $3.9 \mathrm{~cm}$. For those undergoing sublobar resection, the greatest proportion were those with a size less than $2 \mathrm{~cm}(47.7 \%)$. In the sublobar resections, increasing size became progressively less frequent. For those patients who underwent segmentectomy (Table 1), the proportion of tumors less than $2 \mathrm{~cm}$ in diameter and those 2 to $2.9 \mathrm{~cm}$ in diameter was roughly the same $(39.3 \%$ and $35.9 \%)$. For the wedge resection cohort, most $(52.7 \%)$ were less than $2 \mathrm{~cm}$ in diameter and tumor 2 to 2.9 $\mathrm{cm}$ in diameter were found $24.7 \%$ of the time. In all 4 of the Cox proportional hazards models, each incremental increase in tumor size was associated with an increase in the risk of mortality (all-cause and cancer-specific).

On Kaplan-Meier survival analysis, significant differences were found in survival when the tumors were grouped by those less than or equal to $2 \mathrm{~cm}$ and those greater than 2 $\mathrm{cm}$ in diameter (data not shown). For overall and cancerspecific survival, for tumors less than $2 \mathrm{~cm}$ in diameter, the $P$ value was $<.0001$. For tumors greater than $2 \mathrm{~cm}$ in diameter, the $P$ value for overall survival was $<.0001$ and
TABLE 1. Lobectomy versus segmentectomy versus wedge cohort demographics

\begin{tabular}{|c|c|c|c|c|}
\hline Variable & Lobectomy & Segmentectomy & Wedge & $\begin{array}{c}P \\
\text { value }\end{array}$ \\
\hline Patients (n) & 5532 & 152 & 768 & \\
\hline Age $(y)$ & & & & $.003^{*}$ \\
\hline$<40$ & 0.7 & 1.3 & 1.4 & \\
\hline $40-49$ & 5.0 & 3.3 & 5.3 & \\
\hline $50-59$ & 16.3 & 11.8 & 14.5 & \\
\hline $60-69$ & 32.3 & 23.7 & 29.6 & \\
\hline $70-79$ & 35.7 & 42.8 & 37.3 & \\
\hline$>80$ & 10.0 & 17.1 & 12 & \\
\hline Race & & & & $.037 *$ \\
\hline White & 83.7 & 82.2 & 84.3 & \\
\hline Black & 6.6 & 9.2 & 8.63 & \\
\hline Other & 9.7 & 8.6 & 7.06 & \\
\hline Gender & & & & .28 \\
\hline Male & 37.7 & 40.1 & 35 & \\
\hline Female & 62.3 & 59.1 & 65 & \\
\hline Tumor size $(\mathrm{cm})$ & & & & $<.0001 *$ \\
\hline$<2$ & 24.9 & 39.3 & 52.7 & \\
\hline $2-2.9$ & 32.1 & 35.9 & 24.7 & \\
\hline $3-3.9$ & 19.6 & 15.2 & 11.2 & \\
\hline $4-4.9$ & 8.9 & 3.5 & 4.1 & \\
\hline $5-5.9$ & 4.6 & 0.7 & 2.6 & \\
\hline $6-6.9$ & 3 & 0.7 & 1.1 & \\
\hline$\geq 7$ & 7 & 4.8 & 3.7 & \\
\hline $\begin{array}{l}\text { Lymph nodes } \\
\quad \text { examined (n) }\end{array}$ & & & & $<.0001^{*}$ \\
\hline 0 & 8.4 & 43 & 62.8 & \\
\hline $1-10$ & 70.6 & 52.1 & 31.5 & \\
\hline $11-16$ & 13.6 & 4.23 & 4 & \\
\hline$\geq 17$ & 7.5 & 0.7 & 1.8 & \\
\hline Histologic type $(\%)$ & & & & $<.0001^{*}$ \\
\hline $\begin{array}{l}\text { Not otherwise } \\
\text { specified }\end{array}$ & 88.2 & 80.9 & 81.6 & \\
\hline Alveolar carcinoma & 1 & 2 & 0.3 & \\
\hline Nonmucinous & 4.4 & 11.2 & 7.7 & \\
\hline Mucinous & 5.5 & 5.3 & 9.5 & \\
\hline Mixed type & 0.9 & 0.7 & 0.9 & \\
\hline Grade $(\%)$ & & & & $.034^{*}$ \\
\hline Well differentiated & 45.8 & 41.8 & 52.6 & \\
\hline $\begin{array}{l}\text { Moderately } \\
\text { differentiated }\end{array}$ & 42.2 & 48.2 & 35.2 & \\
\hline $\begin{array}{l}\text { Poorly } \\
\quad \text { differentiated }\end{array}$ & 11.5 & 10 & 11.3 & \\
\hline Undifferentiated & 0.6 & 0 & 1 & \\
\hline
\end{tabular}

for cancer-specific survival was .0003 . In the graphs of the survival curves, the segmentectomy and lobectomy curves overlapped. Those with wedge resections did worse.

On multivariate analysis of those tumors less than or equal to $2 \mathrm{~cm}$ in diameter with the Cox proportional hazards model (Table 4), segmentectomies and lobectomies resulted in superior survival compared with wedge resection. No difference was found between segmentectomy and lobectomy 

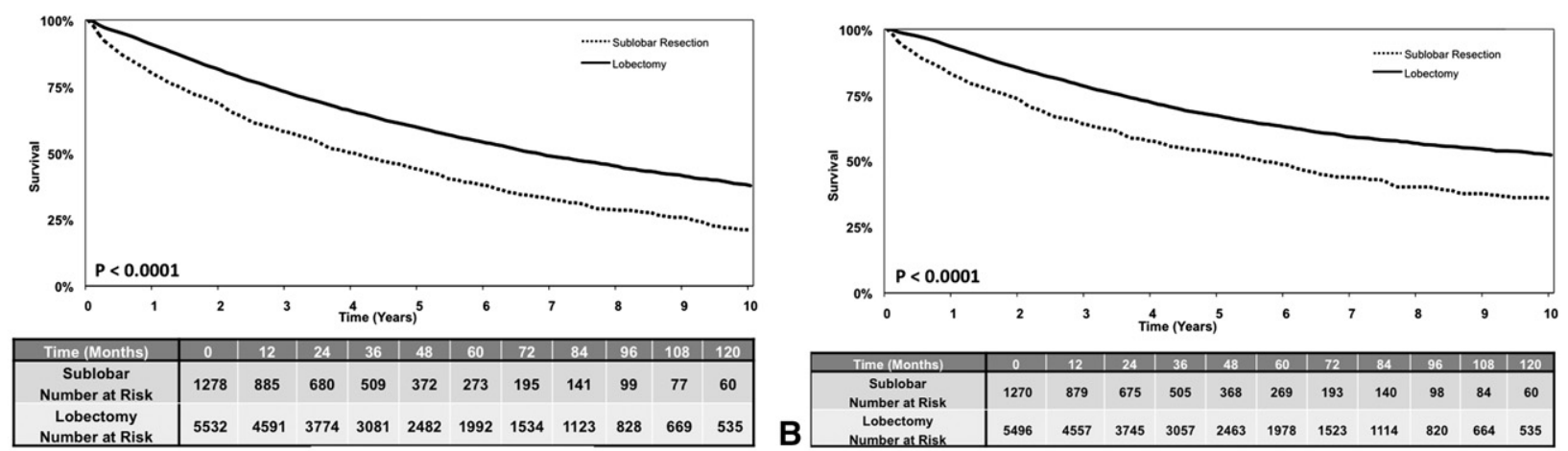

A

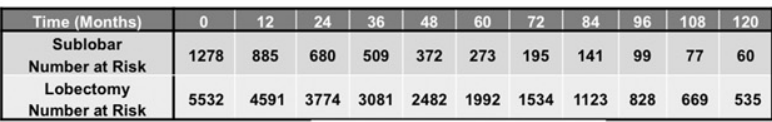

Lobectomy
Number at Ris
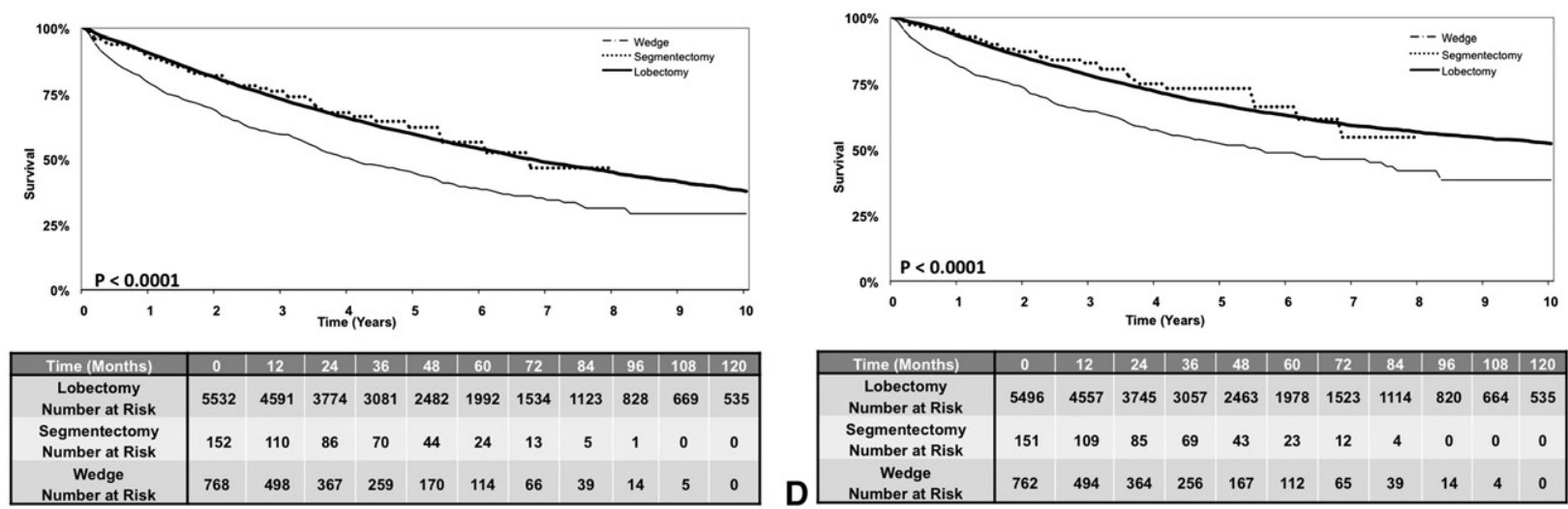

FIGURE 2. (A) Overall survival and (B) cancer-specific survival for patients with bronchoalveolar cell carcinoma histologic features who underwent either lobar or sublobar resection. (C) Overall survival and (D) cancer-specific survival for those patients who underwent anatomic resection (lobectomy or segmentectomy) and nonanatomic resection (wedge resection). Survival denoted on y-axis, with time in months along $\mathrm{x}$-axis. Below the graph, number at risk for each is indicated.

(overall survival, $P=.4095$; cancer-specific survival, $P=.2891)$.

For those tumors greater than $2 \mathrm{~cm}$ in diameter (Table 4), a lobectomy operation was superior to wedge resection. A segmentectomy did not have significantly different survival compared with wedge resection. No difference was found between segmentectomy and lobectomy in terms of survival (overall survival, $P=.6395$; cancer-specific survival, $P=.8606)$.

\section{Lymph Nodes Examined}

In lobar resections, $70.6 \%$ of patients had 1 to 10 lymph nodes examined (Table 1). However, $43 \%$ of segmentectomies and $62.8 \%$ of wedge resections had had no lymph nodes evaluated. Only $4.8 \%$ of the sublobar resections had more than 10 lymph nodes evaluated. In both lobar versus sublobar and anatomic versus nonanatomic resection models, each incremental increase in lymph node numbers evaluated corresponded with an increasingly more favorable hazard ratio for both all-cause and cancer-specific mortality (Tables 2 and 3).

\section{Grade}

Well-differentiated grade BAC was the most prevalent in both lobar and sublobar cohorts. Between the sublobar groups, those undergoing segmentectomy had a greater proportion of moderately differentiated tumors compared with those undergoing wedge resection, who had a greater proportion of well-differentiated tumors (Table 1). In both Cox proportional hazards models, greater degrees of dedifferentiation were associated with greater all-cause and cancer-specific mortality (Tables 2 and 3 ).

\section{DISCUSSION}

In 1995, the Lung Cancer Study Group reported the results of a prospective multi-institutional trial of limited resections for early-stage (American Joint Committee on Cancer Stage I or II NSCLC). The histologic subtypes evaluated in the that landmark analysis were simply classified as nonsquamous and squamous. ${ }^{8}$ Since then, adenocarcinoma (one of many "nonsquamous" histologic types) and its histologic subtypes (eg, BAC) have become increasingly important. In particular, our evolving understanding of the natural history and biologic behavior of BAC has brought into question the generalizability of the Lung Cancer Study Group findings for patients with BAC. ${ }^{10-12,21,22}$

Although it is a relatively rare subtype (approximately $4 \%$ of NSCLC histologic types), ${ }^{11,23,24}$ BAC has a distinct natural history compared with other NSCLC 
TABLE 2. Cox proportional hazards regression model for all-cause and cancer-specific mortality for lobar versus sublobar resection

\begin{tabular}{|c|c|c|}
\hline Variable & $\begin{array}{l}\text { All-cause } \\
\text { mortality* }\end{array}$ & $\begin{array}{c}\text { Cancer-specific } \\
\text { mortality* }\end{array}$ \\
\hline \multicolumn{3}{|l|}{ Surgical approach } \\
\hline Sublobar & Reference & Reference \\
\hline Lobectomy & $0.56(0.51-0.62)$ & $0.53(0.48-0.6)$ \\
\hline \multicolumn{3}{|l|}{ Age $(y)$} \\
\hline$<40$ & Reference & Reference \\
\hline $40-49$ & $0.84(0.53-1.32)$ & $0.82(0.51-1.31)$ \\
\hline $50-59$ & $0.92(0.6-1.3)$ & $0.8(0.51-1.26)$ \\
\hline $60-69$ & $1.11(0.74-1.69)$ & $0.93(0.6-1.61)$ \\
\hline $70-79$ & $1.38(0.91-2.09)$ & $1.04(0.67-1.61)$ \\
\hline$>80$ & $1.92(1.26-2.94)$ & $1.27(0.81-2)$ \\
\hline \multicolumn{3}{|l|}{ Race } \\
\hline White & Reference & Reference \\
\hline Black & $1.22(1.07-1.41)$ & $1.28(1.1-1.5)$ \\
\hline Other & $1.05(0.91-1.21)$ & $1.1(0.93-1.3)$ \\
\hline \multicolumn{3}{|l|}{ Gender } \\
\hline Female & Reference & Reference \\
\hline Male & $1.53(1.42-1.65)$ & $1.43(1.31-1.56)$ \\
\hline \multicolumn{3}{|l|}{ Tumor size $(\mathrm{cm})$} \\
\hline$<2$ & Reference & Reference \\
\hline $2-2.9$ & $1.01(0.91-1.11)$ & $0.95(0.84-1.07)$ \\
\hline $3-3.9$ & $1.28(1.15-1.43)$ & $1.26(1.11-1.44)$ \\
\hline $4-4.9$ & $1.94(1.69-2.23)$ & $2.08(1.77-2.44)$ \\
\hline $5-5.9$ & $1.83(1.54-2.18)$ & $2.0(1.64-2.44)$ \\
\hline $6-6.9$ & $2.53(2.04-3.12)$ & $2.93(2.32-3.7)$ \\
\hline$\geq 7$ & $3.6(3.13-4.14)$ & $4.37(3.74-5.09)$ \\
\hline \multicolumn{3}{|l|}{ Lymph nodes examined (n) } \\
\hline 0 & Reference & Reference \\
\hline $1-10$ & $0.83(0.76-0.9)$ & $0.81(0.74-0.89)$ \\
\hline $11-16$ & $0.7(0.61-0.81)$ & $0.69(0.58-0.81)$ \\
\hline$\geq 17$ & $0.65(0.54-0.8)$ & $0.67(0.54-0.84)$ \\
\hline \multicolumn{3}{|l|}{ Grade } \\
\hline Well differentiated & Reference & Reference \\
\hline Moderately differentiated & $1.4(1.27-1.54)$ & $1.39(1.23-1.56)$ \\
\hline Poorly differentiated & $2.13(1.88-2.42)$ & $2.51(2.17-2.9)$ \\
\hline Undifferentiated & $1.34(1.22-1.48)$ & $1.38(1.23-1.55)$ \\
\hline
\end{tabular}

Data presented as hazard ratio, with $95 \%$ confidence intervals in parentheses. *Hazard ratios adjusted for cancer registry (to adjust for geography).

histologic types. ${ }^{24,25}$ A previous analysis of the SEER data set revealed that BAC is associated with superior survival rates compared with other histologic types. ${ }^{24}$ Data from single-institution studies have supported this finding. Campione and colleague ${ }^{25}$ evaluated 224 patients with Stage IA NSCLC, of whom 54 had BAC. These 54 patients with BAC were found to have significantly $(P=.04)$ superior 5-year survival $(88 \%)$ compared with all other histologic types $(54 \%)$. On multivariate analysis, they found that nonBAC NSCLC histologic features were independently associated with a sevenfold increased risk of death.

The traditional approach to BAC surgical treatment has, to some degree, revolved around the radiographic appearance. ${ }^{13,21,26,27}$ Infiltrative lesions, based on the radiographic appearance, have correlated with mucinous histologic
TABLE 3. Cox proportional hazards regression model for all-cause and cancer-specific mortality for lobar versus segmentectomy versus wedge resections

\begin{tabular}{|c|c|c|}
\hline Variable & $\begin{array}{l}\text { All-cause } \\
\text { mortality* }\end{array}$ & $\begin{array}{c}\text { Cancer-specific } \\
\text { mortality* }\end{array}$ \\
\hline \multicolumn{3}{|l|}{ Surgical approach } \\
\hline Wedge & Reference & Reference \\
\hline Segmentectomy & $0.58(0.42-0.79)$ & $0.49(0.33-0.72)$ \\
\hline Lobectomy & $0.53(0.47-0.61)$ & $0.49(0.42-0.56)$ \\
\hline \multicolumn{3}{|l|}{ Age (y) } \\
\hline$<40$ & Reference & Reference \\
\hline $40-49$ & $0.92(0.56-1.51)$ & $0.93(0.55-1.57)$ \\
\hline $50-59$ & $1.07(0.67-1.7)$ & $0.96(0.58-1.57)$ \\
\hline $60-69$ & $1.26(0.8-1.99)$ & $1.08(0.66-1.75)$ \\
\hline $70-79$ & $1.53(0.97-2.42)$ & $1.21(0.74-1.96)$ \\
\hline$>80$ & $2.19(1.37-3.48)$ & $1.50(0.91-2.48)$ \\
\hline \multicolumn{3}{|l|}{ Race } \\
\hline White & Reference & Reference \\
\hline Black & $1.26(1.09-1.45)$ & $1.32(1.12-1.55)$ \\
\hline Other & $1.06(0.91-1.23)$ & $1.09(0.92-1.57)$ \\
\hline \multicolumn{3}{|l|}{ Gender } \\
\hline Female & Reference & Reference \\
\hline Male & $1.53(1.42-1.66)$ & $1.44(1.31-1.57)$ \\
\hline \multicolumn{3}{|l|}{ Tumor size $(\mathrm{cm})$} \\
\hline$<2$ & Reference & Reference \\
\hline $2-2.9$ & $1.04(0.93-1.16)$ & $0.99(0.87-1.13)$ \\
\hline $3-3.9$ & $1.33(1.18-1.5)$ & $1.32(1.15-1.52)$ \\
\hline $4-4.9$ & $1.97(1.71-2.27)$ & $2.12(1.8-2.5)$ \\
\hline $5-5.9$ & $1.84(1.54-2.21)$ & $1.99(1.61-2.46)$ \\
\hline $6-6.9$ & $2.52(2.03-3.13)$ & $2.97(2.33-3.77)$ \\
\hline$\geq 7$ & $3.71(3.21-4.29)$ & $4.54(3.87-5.33)$ \\
\hline \multicolumn{3}{|l|}{ Lymph nodes examined } \\
\hline 0 & Reference & Reference \\
\hline $1-10$ & $0.85(0.78-0.93)$ & $0.84(0.76-0.93)$ \\
\hline $11-16$ & $0.73(0.63-0.84)$ & $0.71(0.59-0.84)$ \\
\hline$\geq 17$ & $0.66(0.54-0.81)$ & $0.68(0.54-0.86)$ \\
\hline \multicolumn{3}{|l|}{ Grade } \\
\hline Well differentiated & Reference & Reference \\
\hline Moderately differentiated & $1.44(1.30-1.6)$ & $1.45(1.28-1.63)$ \\
\hline Poorly differentiated & $2.23(1.96-2.55)$ & $2.62(2.26-3.05)$ \\
\hline Undifferentiated & $1.38(1.24-1.53)$ & $1.42(1.26-1.61)$ \\
\hline
\end{tabular}

Data presented as hazard ratios and $95 \%$ confidence intervals. *Hazard ratios adjusted for cancer registry (to adjust for geography).

features. Mass-like lesions have correlated with nonmucinous histologic features. ${ }^{13}$ Some investigators have attempted to ascertain methods to identify in situ lesions. Ohori and Santa Maria $^{28}$ evaluated broncheoalveolar lavage cytology specimens and histologic features. They found that although a component of in situ histologic features was present, the final determination would involve a correlation with a combination of clinical, radiographic, and histologic data. ${ }^{28}$

In recent years, the interest in limited anatomic resections (ie, segmentectomies) has increased. ${ }^{4-7}$ This is, to some degree, driven by a desire to limit the extent of parenchymal resection ${ }^{1-3}$ and preserve as much functional 
TABLE 4. Cox proportional hazards regression model for all-cause and cancer-specific mortality for lobar versus segmentectomy versus wedge resections grouped by tumor diameter (size)

\begin{tabular}{lcc}
\hline Surgical approach & $\begin{array}{c}\text { All-cause } \\
\text { mortality* }\end{array}$ & $\begin{array}{c}\text { Cancer-specific } \\
\text { mortality* }\end{array}$ \\
\hline $\begin{array}{l}\text { Tumor } \leq 2 \mathrm{~cm} \\
\text { Wedge }\end{array}$ & $\begin{array}{c}\text { Reference } \\
\text { Segmentectomy }\end{array}$ & $\begin{array}{c}\text { Reference } \\
\text { Lobectomy }\end{array}$ \\
$\begin{array}{l}\text { Tumor }>2 \mathrm{~cm} \\
\text { Wedge }\end{array}$ & $0.53(0.27-0.71)$ & $0.34(0.18-0.62)$ \\
$\begin{array}{l}\text { Segmentectomy } \\
\text { Lobectomy }\end{array}$ & Reference & $0.47(0.38-0.57)$ \\
$\begin{array}{l}\text { Data presented as hazard ratio, with } 95 \% \text { confidence intervals in parentheses. } * \text { Haz- } \\
\text { ard ratios adjusted for cancer registry (to adjust for geography), age in decades, race, } \\
\text { gender, grade of tumor, and lymph node number. }\end{array}$ & Reference \\
\end{tabular}

tissue as possible. Furthermore, given the superior survival rates in patients with $\mathrm{BAC}$, the benefit of lobectomy for these patients is uncertain. The role of a nonanatomic resection for the treatment of $\mathrm{BAC}$ has been advocated. ${ }^{15,16,29,30}$ Previous studies that examined the effect of the extent of resection on survival in patients with BAC have been limited to single-institutional series. ${ }^{17-19}$

Consequently, we used a large population data set to examine the effect of the extent of resection on survival in patients with BAC. We found that patients who underwent anatomic resection (ie, segmentectomy or lobectomy) had superior survival rates compared with those undergoing nonanatomic resection (ie, wedge resection). Its pattern of spread might explain our finding of improved survival with anatomic resection.

By definition, tumors that are pure BAC infiltrate along the bronchial and alveolar structure and should not metastasize to the lymph nodes. However, what we have found in our data was that there does appear to be a role for lymph node evaluation in the treatment of these patients. These data are likely a surrogate for the inaccuracy in the pathologic evaluation of the tumors. These tumors might have had other histologic subtypes involved. Alternatively, they were coded as BAC because their histologic findings had BAC features.

Histologically, BAC arises from terminal bronchiolar and acinar epithelial tissue. It has a "lepidic" pattern of growth (growth along pre-existing alveolar structures). To some degree, this limits its invasiveness, as demonstrated by a lack of stromal, vascular, or pleural invasion. ${ }^{21}$ As a consequence of this pattern of spread, anatomic resection might provide improved outcomes by removing residual areas or tumor nests or removing the draining lymphatics.

Its degree of differentiation and its typical pattern of spread might explain improve outcomes with BAC. The BAC grade typically found on pathologic examination is well differentiated or moderately differentiated. ${ }^{21}$ In our study, we also found this to be true. Well-differentiated and moderately differentiated grades of tumors were the greatest proportion of tumors.

BAC lesions have a tendency to be nodular or a consolidative/lobar process. ${ }^{21}$ Dumont and colleagues ${ }^{26}$ evaluated 97 patients with BAC and found that $85 \%$ presented as nodules and $15 \%$ as a pneumonitis or diffusely infiltrative process. Mucinous histologic features comprised $43 \%$ of specimens, and $12 \%$ were multicentric or diffuse. ${ }^{26}$ Invasive patterns are predictive of survival. ${ }^{27}$ The pathologic findings correlate with the computed tomography (CT) findings.

Sawada and colleagues ${ }^{31}$ found that BAC tends to have a solid or partly solid attenuation pattern with aircontaining spaces and a lack of contractive features. BAC tumors also demonstrate a low maximum standardized uptake value on fluordeoxyglucose positron emission tomography (PET). ${ }^{31}$ Bryant and Cerfolio ${ }^{32}$ found that the maximal standardized uptake value of CT/PET had difficulty in predicting the malignant nature of BAC histologic features. In their study of 585 patients with pulmonary nodules, of which 496 ultimately were found to be malignant, 23 had BAC histologic features. A total of 17 falsenegative results were found with CT/PET imaging. BAC constituted 11 , or $65 \%$ (11 of 17 ), of all the falsenegative findings and $48 \%$ (11 of 23 ) of all the patients with BAC.

With this degree of intraparenchymal spread and the inability to localize or predict BAC pathology clinically with CT/PET, we sought to determine whether the variations in the extent of resection for BAC histologic features were appropriate in terms of their influence on survival.

Through multivariate analysis, we found that lobar resection did yield superior overall all-cause and cancer-specific mortality compared with sublobar resection. Additionally, we found that when an anatomic resection was performed, compared with a nonanatomic wedge resection, similar superior overall all-cause and cancer-specific mortality was obtained. This makes intuitive sense when one reflects on the histologic nature of $\mathrm{BAC}$ and its lepidic growth pattern described.

With our Cox proportional hazard models, we uniformly found that an increasing tumor size correlated with an increase in the hazard ratio for mortality. Not surprisingly, this has been echoed in the published NSCLC data. ${ }^{25}$ In addition, this has been found in the BAC-specific data. Campione and colleagues ${ }^{25}$ found that those with tumors less than $2 \mathrm{~cm}$ in diameter had improved survival $(P=.0109)$. Similarly, in a study by Oka and colleagues ${ }^{33}$ in which the mucinous BAC subset of NSCLC was studied, they found that lesions less than $3 \mathrm{~cm}$ had 5-year survival of $100 \%$ and those with tumor greater than $3 \mathrm{~cm}$ had survival of only $25.1 \%$. Although the Pittsburgh group has suggested that lesions less than $2 \mathrm{~cm}$ might be amenable to 
segmental resection, ${ }^{7}$ Bilfinger and Baram ${ }^{15}$ have suggested that for segmentectomy to be performed for BAC, the lesion should be less than $2 \mathrm{~cm}$ in diameter and the margin greater than $2 \mathrm{~cm}$. These criteria are in evolution.

BAC has been associated with the young, those with limited or no smoking history, and those of Asian descent. ${ }^{12} \mathrm{We}$ found that women constituted a greater proportion of the cases than did men and that most patients were selfdescribed as white. An explanation for why the distribution of race in our study was predominantly white could be a reflection of the distribution of white and Asian people found in the United States. In our multivariate analysis, women did fare significantly better than men. Blacks had a greater hazard ratio of mortality. Age did not appear to be associated with an increased risk, except for those older than 80 years, in the all-cause mortality analysis.

The implications of these data presented in the present report will undoubtedly be an interpretation in process as the International Association for the Study of Lung Cancer redefined BAC in early 2011. ${ }^{14}$ In that publication, Travis and colleagues ${ }^{14}$ stated that the terms "BAC" and "mixed subtype adenocarcinoma" should be removed from use. Lesions with pure lepidic growth should be classified as adenocarcinoma in situ and those with a predominant lepidic growth and less than $5 \mathrm{~mm}$ of invasion should be defined as minimally invasive adenocarcinoma. The term "invasive adenocarcinoma" is added with multiple variants. Mucinous BAC is reclassified as invasive mucinous adenocarcinoma. ${ }^{14}$ Although the nomenclature has changed, the concepts for the separate histologic types remain.

The spectrum of lung adenocarcinoma might not be a continuum. Yatabe and colleagues ${ }^{34}$ have commented that the distribution might be more the results of different molecular pathway involvement. This perspective might be the most accurate.

With the recent International Association for the Study of Lung Cancer nomenclature change, several investigators have re-evaluated the long-term outcomes of NSCLC resection with the new classification. What they found is that the degree of invasiveness might be more of a prognosticator than previously thought. In their re-evaluation of 514 patients with Stage I adenocarcinoma, Yoshizawa and colleagues $^{35}$ found 3 degrees of invasiveness: low, intermediate, and high. Of those patients with a "low" classification (adenocarcinoma in situ and minimally invasive adenocarcinoma), the 5-year survival was $100 \%$. In the "intermediate" group (nonmucinous lepidic predominant, papillary predominant, and acinar predominant), the 5 -year survival was $83 \%$ to $90 \%$. For the "high" group (invasive mucinous adenocarcinoma, colloid predominant, solid predominant, and micropapillary), the 5-year survival was $67 \%$ to $71 \%{ }^{35}$ Russell and colleagues ${ }^{36}$ re-evaluated 210 patients. Those who were found to have adenocarcinoma in situ, minimally invasive adenocarcinoma, or lepidic predominant adenocarcinoma histologic types had near $100 \%$ 5-year survival. ${ }^{36}$

The Kaplan-Meier survival curves that our data have generated could represent 3 possible scenarios. The first is that these are the true survival of patients with BAC who were surgically treated. They might also represent those of patients with mixed cell histologic types. There might be more aggressive histologic types included with the BAC cell type. If these more aggressive tumors were underrecognized, the tumor size, degree of lymphadenectomy, and extent of the resection would undoubtedly play a more important role. If an intermediate grade is present, a slow steady decline could be interpreted. The latter 2 possibilities could be representative in the curves in the early or late portions, respectively.

In patients with mixed histologic features, treatment should be based on the non-BAC histologic type. The size, degree of lymph node involvement, pulmonary function, and anatomic location should all be taken into account in the decision to perform wedge resection, segmentectomy, or lobectomy in their treatment. With time, what might be seen is an effect similar to that reported by Zell and colleagues ${ }^{37}$ after the 1999 World Health Organization reclassification in which survival improved, and this might have resulted from the more accurate classification.

\section{Strengths and Limitations}

We used retrospective data and, as such, our study had the inherent limitations of all observational studies, particularly selection bias. A myriad of clinical data are considered during the operative selection of patients; however, we were unable to account for all these factors. No coded variables or data on patient fitness or pulmonary function are available, either at resection or after. Also, the data are coded by the local data registrar. The guidelines for data registry are provided by the National Cancer Institute's SEER. The data set spans 3 decades, and the pathologic evaluation and classification has changed (most recently at the World Health Organization consensus conference in November 2004 with the International Association for the Study of Lung Cancer and American Society of Clinical Oncology). Data on the 2011 BAC nomenclature changes ${ }^{14}$ were not reflected in the data set.

The data coded in the SEER database are that of the dominant histologic findings. The argument that might have been miscoded and as such the outcomes might not have been driven by the BAC component but by the mixed histologic features not reported is conceded. Institutional variations in pathologic reporting describing adenocarcinoma with BAC features might have affected the classification in SEER. Future submissions to the SEER database should be adjusted to the new International Association for the Study of Lung Cancer coding changes of adenocarcinoma in situ, minimally invasive adenocarcinoma, and invasive adenocarcinoma. 
Our study also had the inherent limitations of common to the SEER database. In particular, we could not assess the surgical approach (ie, thoracotomy vs thoracoscopy), surgeon or hospital volume, tumor recurrence, pretreatment staging, or use of chemotherapy. Data on whether mediastinal lymph node evaluation was used or the method undertaken were not available.

Despite these limitations, our study had a number of strengths. We had a large cohort, with more than 6800 patients included in our study. Although our study was neither prospective nor randomized, it was multi-institutional. Because our study used population-based data, it reflects the practice and patterns of care across the United States and is an accurate reflection of the outcomes and treatment of the population of patients treated.

\section{CONCLUSIONS}

Using the National Cancer Institute population-based SEER data set, we have found that in patients with BAC histologic features, undergoing lobar or anatomic resection does confer a significant survival advantage compared with sublobar or nonanatomic resection. Increasing tumor size portends an increased mortality risk. More extensive lymphadenectomy also appears to be beneficial. This finding might result from mixed tumor histologic features. More de-differentiated tumors have worse prognoses than do well-differentiated tumors. A move to the new nomenclature ${ }^{14}$ should be adopted. The terms adenocarcinoma in situ, minimally invasive adenocarcinoma, and the predominant cell type should be the standard and replace the term "bronchoalveolar carcinoma." These findings have potentially important implications for thoracic surgeons and warrant additional detailed investigation.

\section{References}

1. Lucchi M, Melfi F, Ribechini A, Dini P, Duranti L, Fontanini G, et al. Sleeve and wedge parenchyma-sparing bronchial resections in low-grade neoplasms of the bronchial airway. J Thorac Cardiovasc Surg. 2007;134:373-7.

2. Rendina EA, Venuta F, de Giacomo T, Rossi M, Coloni GF. Parenchymal sparing operations for bronchogenic carcinoma. Surg Clin North Am. 2002;82:589-609, vii.

3. Yavuzer S, Yuksel C, Kutlay H. Segmental bronchial sleeve resection: preserving all lung parenchyma for benign/low-grade neoplasms. Ann Thorac Surg. 2010; 89:1737-43.

4. Okumura M, Goto M, Ideguchi K, Tamura M, Sasaki H, Tanaka H, et al. Factors associated with outcome of segmentectomy for non-small cell lung cancer: longterm follow-up study at a single institution in Japan. Lung Cancer. 2007;58: 231-7.

5. Okada M, Nishio W, Sakamoto T, Uchino K, Yuki T, Nakagawa A, Tsubota N. Effect of tumor size on prognosis in patients with non-small cell lung cancer: the role of segmentectomy as a type of lesser resection. $J$ Thorac Cardiovasc Surg. 2005; 129:87-93.

6. Shapiro M, Weiser TS, Wisnivesky JP, Chin C, Arustamyan M, Swanson SJ. Thoracoscopic segmentectomy compares favorably with thoracoscopic lobectomy for patients with small stage I lung cancer. J Thorac Cardiovasc Surg. 2009;137:1388-93.

7. Schuchert MJ, Pettiford BL, Keeley S, D'Amato TA, Kilic A, Close J, et al. Anatomic segmentectomy in the treatment of stage I non-small cell lung cancer. Ann Thorac Surg. 2007;84:926-33.
8. Ginsberg RJ, Rubinstein LV; Lung Cancer Study Group. Randomized trial of lobectomy versus limited resection for T1 N0 non-small cell lung cancer. Ann Thorac Surg. 1995;60:615-23.

9. Whitson BA, Groth SS, Andrade RS, Maddaus MA, Habermann EB, D'Cunha J. Survival after lobectomy vs. segmentectomy for stage I non-small cell lung cancer: a population-based analysis. Ann Thorac Surg. 2011;92:1943-50.

10. Travis WD, Garg K, Franklin WA, Wistuba II, Sabloff B, Noguchi M, et al. Bronchioloalveolar carcinoma and lung adenocarcinoma: the clinical importance and research relevance of the 2004 World Health Organization pathologic criteria. J Thorac Oncol. 2006;1:S13-9.

11. Levy BP, Drilon A, Makarian L, Patel AA, Grossbard ML. Systemic approaches for multifocal bronchioloalveolar carcinoma: is there an appropriate target? Oncology (Williston Park). 2010;24:888-98, 900.

12. Garfield DH, Cadranel JL, Wislez M, Franklin WA, Hirsch FR. The bronchioloalveolar carcinoma and peripheral adenocarcinoma spectrum of diseases. J Thorac Oncol. 2006;1:344-59.

13. Okubo K, Mark EJ, Flieder D, Wain JC, Wright CD, Moncure AC, et al. Bronchoalveolar carcinoma: clinical, radiologic, and pathologic factors and survival. J Thorac Cardiovasc Surg. 1999;118:702-9.

14. Travis WD, Brambilla E, Noguchi M, Nicholson AG, Geisinger KR, Yatabe Y, et al. International association for the Study of Lung Cancer/American Thoracic Society/European Respiratory Society International multidisciplinary classification of lung adenocarcinoma. J Thorac Oncol. 2011;6:244-85.

15. Bilfinger TV, Baram D. Sublobar resection in nonsmall cell lung carcinoma. Curr Opin Pulm Med. 2008;14:292-6.

16. Rusch VW, Tsuchiya R, Tsuboi M, Pass HI, Grunenwald D, Goldstraw P. Surgery for bronchioloalveolar carcinoma and "very early" adenocarcinoma: an evolving standard of care? J Thorac Oncol. 2006;1:S27-31.

17. Yamato Y, Tsuchida M, Watanabe T, Aoki T, Koizumi N, Umezu H, et al. Early results of a prospective study of limited resection for bronchioloalveolar adenocarcinoma of the lung. Ann Thorac Surg. 2001;71:971-4.

18. Watanabe S, Watanabe T, Arai K, Kasai T, Haratake J, Urayama H. Results of wedge resection for focal bronchioloalveolar carcinoma showing pure groundglass attenuation on computed tomography. Ann Thorac Surg. 2002;73:1071-5.

19. Sakurai H, Dobashi Y, Mizutani E, Matsubara H, Suzuki S, Takano K, et al. Bronchioloalveolar carcinoma of the lung 3 centimeters or less in diameter: a prognostic assessment. Ann Thorac Surg. 2004;78:1728-33.

20. Ludwig MS, Goodman M, Miller DL, Johnstone PA. Postoperative survival and the number of lymph nodes sampled during resection of node-negative non-small cell lung cancer. Chest. 2005;128:1545-50.

21. Travis WD, Brambilla E, Muller-Hermelink HK, Harris CC, eds. World Health Organization, International Agency for Research on Cancer, International Association for the Study of Lung Cancer, International Academy of Pathology, Pathology and Genetics of Tumours of the Lung, Pleura, Thymus and Heart. Oxford, England: IARC Press, Oxford University Press; 2004:10-25, 35-44.

22. Raz DJ, Kim JY, Jablons DM. Diagnosis and treatment of bronchioloalveolar carcinoma. Curr Opin Pulm Med. 2007;13:290-6.

23. McVay CL, Pickens A, Fuller C, Houck W, McKenna R Jr. VATS anatomic pulmonary resection in octogenarians. Am Surg. 2005;71:791-3.

24. Read WL, Page NC, Tierney RM, Piccirillo JF, Govindan R. The epidemiology of bronchioloalveolar carcinoma over the past two decades: analysis of the SEER database. Lung Cancer. 2004;45:137-42.

25. Campione A, Ligabue T, Luzzi L, Ghiribelli C, Paladini P, Voltolini L, et al. Impact of size, histology, and gender on stage IA non-small cell lung cancer. Asian Cardiovasc Thorac Ann. 2004;12:149-53.

26. Dumont P, Gasser B, Rouge C, Massard G, Wihlm JM. Bronchoalveolar carcinoma: histopathologic study of evolution in a series of 105 surgically treated patients. Chest. 1998;113:391-5.

27. Schmidt L, Myers J. Bronchioloalveolar carcinoma and the significance of invasion: predicting biologic behavior. Arch Pathol Lab Med. 2010;134:1450-4.

28. Ohori NP, Santa Maria EL. Cytopathologic diagnosis of bronchioloalveolar carcinoma: does it correlate with the 1999 World Health Organization definition? Am J Clin Pathol. 2004;122:44-50.

29. Yoshioka M, Ichiguchi O. Selection of sublobar resection for c-stage IA nonsmall cell lung cancer based on a combination of structural imaging by $\mathrm{CT}$ and functional imaging by FDG PET. Ann Thorac Cardiovasc Surg. 2009;15:82-8.

30. Yoshida J. Management of the peripheral small ground-glass opacities. Thorac Surg Clin. 2007;17:191-201, viii.

31. Sawada E, Nambu A, Motosugi U, et al. Localized mucinous bronchioloalveolar carcinoma of the lung: thin-section computed tomography and fluorodeoxyglucose positron emission tomography findings. Jpn J Radiol. 2010;28:251-8. 
32. Bryant AS, Cerfolio RJ. The maximum standardized uptake values on integrated FDG-PET/CT is useful in differentiating benign from malignant pulmonary nodules. Ann Thorac Surg. 2006;82:1016-20.

33. Oka S, Hanagiri T, Uramoto H, et al. Surgical resection for patients with mucinous bronchioloalveolar carcinoma. Asian J Surg. 2010;33:89-93.

34. Yatabe Y, Borczuk AC, Powell CA. Do all lung adenocarcinomas follow a stepwise progression? Lung Cancer. 2011;74:7-11.

35. Yoshizawa A, Motoi N, Riely GJ, Sima CS, Gerald WL, Kris MG, et al. Impact of proposed IASLC/ATS/ERS classification of lung adenocarcinoma: prognostic subgroups and implications for further revision of staging based on analysis of 514 stage I cases. Mod Pathol. 2011;24:653-64.

36. Russell PA, Wainer Z, Wright GM, Daniels M, Conron M, Williams RA. Does lung adenocarcinoma subtype predict patient survival?: a clinicopathologic study based on the new International Association for the Study of Lung Cancer/American Thoracic Society/European Respiratory Society international multidisciplinary lung adenocarcinoma classification. J Thorac Oncol. 2011;6:1496-504.

37. Zell JA, Ou SH, Ziogas A, Anton-Culver H. Epidemiology of bronchioloalveolar carcinoma: improvement in survival after release of the 1999 WHO classification of lung tumors. J Clin Oncol. 2005;23:8396-405.

\section{Discussion}

Dr Ross Bremner (Phoenix, Ariz). Thanks very much, Bryan. What a great presentation, and thank you for a well-written report.

Your study has attempted to clarify a surgical approach to bronchoalveolar cell carcinoma (BAC) using this large cohort of patients from the Surveillance, Epidemiology, and End Results (SEER) database and from a long time period, from 1998 to 2007. It does suffer from the limitations of the SEER database, which have already been discussed at this meeting, but I laud your attempt to try to provide some clarification on how we should approach these patients.

The term "BAC" was originally coined to describe this lipidic growth pattern of a well-differentiated noninvasive cancer, and a paradigm was developed that because these lesions are noninvasive and well behaved that we should perform a parenchymal-sparing operation and that wedge resection is actually acceptable. I would say that probably this is how we mostly approach these lesions throughout the United States. This report challenges that and concludes that a more formal resection, such as lobectomy or formal segmentectomy, is necessary. However, our understanding and classification of this so-called BAC has changed a lot since 1988, making interpretation of these data quite difficult. I am quite sure that your data include some patients that we would now say have a diagnosis of invasive carcinoma in a background of BAC, which is really a different disease. Thus, my first question is, can you clarify what you think the pathology is in these patients? As you know, we now have a more recent classification of adenocarcinoma in situ, minimally invasive adenocarcinoma, and lipidic-predominant adenocarcinoma, all of which actually have about 100\% 5-year survival if we resect the tumor. What do you think the pathology is in this retrospective database? Also, do you think that there is any way we can try to clarify the pathology? Is there any mechanism where we could go back historically to do that?

Dr Whitson. Yes, answers to some of those questions we can attempt to obtain from the data we have available. Some we cannot. From what is coded in the SEER registry, you are very correct-it covers essentially 2 decades worth of data. The predominant cell type is what is recorded by the registrars and we are unfortunately left to the registrar's discretion or the pathologist who interprets those slides as to what that is and how it is reported. For our evaluation, we selected those that were coded as bronchoalveolar as the predominant cell type. Those that were mostly adenocarcinoma, we excluded. However, given the size and span of the registries over the entire United States, there is sure to be some overlap, depending on who interpreted those slides.

What we could do to try to answer your question about looking at some of the more recent histologic classifications that came out through International Association for the Study of Lung Cancer in the spring, although we cannot go back to these data and say what is a lepidic growth pattern versus those that are not, we could look at mucinous histologic findings and those that are nonmucinous and that might be a way to interpret the invasive mucinous adenocarcinomas. That is the extent of the data that we have from the SEER database.

Dr Bremner. I would submit to you that there is a danger in this report that the difference that we see between these groups of patients is that they have included invasive carcinoma, which we would not include in our current diagnosis of - a term that I think needs to be dropped, which I think is BAC - a term that we will soon not be using anymore.

Dr Whitson. I think as we go forward, that term-bronchoalveolar carcinoma-is going to go away and you have adenocarcinoma in situ, invasive mucinous adenocarcinoma, and such. How these get coded in the SEER database and how we look at things from an institutional perspective in comparing previous data to data going forward is going to have to be looked at quite carefully.

Dr Bremner. I imagine that pulmonary function played a role in the surgeon's decision to do either wedge or lobectomy. Do you have any data on the pulmonary function test findings in these patients?

Dr Whitson. No. Unfortunately, no data on pulmonary function test findings or fitness in the SEER data.

Dr Bremner. Just to reiterate, I worry that we are going to send a message that patients who have BAC now need to undergo lobectomy when, our current histology and understanding, is that BAC is really going to be a noninvasive lesion and should be approached with parenchymal-sparing surgery.

Thanks very much and I am sure this was a fantastic exercise in lots of statistics.

Dr Whitson. Thank you very much. I would take Dr Bremner a different perspective. I would not necessarily say that they all need to undergo lobectomy, but we need to look at that data in concert with some of the data coming from the Cancer and Leukemia Group B trial about the tumor size. If one had a small lesion, perhaps wedge resection is adequate-I don't know, segmentectomy-probably for sure for those less than 2-cm lesions. The decision would be determined by the cell type and whether it were a pure histologic type or not. Lymphadenectomies are not being performed. That might be as much or as more important as performing the anatomic resection just as a surrogate. In theory, lymph nodes are not important in BAC, but as we have shown from these data, they do appear to be involved in some fashion.

Dr Douglas Wood (Seattle, Wash). I am going to pick up where Ross left off and also be critical-I am sorry-because I think that this report, despite being technically very well done, is providing a dangerous and regressive message that is actually erroneous for exactly the reasons that Ross just interpreted. Unfortunately, the SEER database, with which I am very familiar, has no ability to discriminate between our current definitions of noninvasive 
carcinoma, which is what BAC in its pure form is, and adenocarcinoma with bronchoalveolar features, which is just invasive adenocarcinoma. By definition, pure bronchoalveolar carcinoma is a noninvasive tumor and therefore it does not have the ability to develop lymphatic invasion that would involve the lymph nodes; thus, your whole premise of the extent of lymph node dissection is not justified and neither is your argument about the extent of parenchymal resection. By definition, a noninvasive cancer does not have access to the lymphatics and it is not able to spread to the lymph nodes. Now, you are right that there might be a component of invasive carcinoma within that apparent bronchoalveolar carcinoma so there could be the occasional error; however, by our current better definitions of pathologic analysis of pure bronchoalveolar carcinoma or noninvasive tumor, the extent of lymph node involvement or dissection should not matter. So, I am worried about the wrong message being delivered when we have become better at defining a patient population that does not require lobectomy. Others will misinterpret your findings that obviously include a wide spectrum of invasive carcinoma as potentially pushing us back toward more aggressive resection for pure bronchoalveolar carcinoma or noninvasive adenocarcinoma.

Dr Whitson. That is a very good point, and we do need to look critically at that.

Dr Scott Swanson (Boston, Mass). I liked the report. One question about your survival analysis in terms of anatomic or nonanatomic. Is that independent of lymph nodes or is that associated with the nodal removal?

Dr Whitson. Those 4 categories of lymph node evaluationyou mean for the Kaplan-Meier curve?

Dr Swanson. Yes, when you showed survival by lobectomy segmentectomy versus wedge. Is that independent of nodal sampling? Is that univariate or multivariate?

Dr Whitson. That was a multivariate analysis, but it was with the lymph nodes not evaluated as a continuous variable but as those 4 subcategories of 0,1 to 10,11 to 16 , or greater than 17 .

Dr Swanson. So an anatomic resection independent of nodal removal is a better option.
Dr Whitson. Better than a wedge, yes, sir, but given the histologic conversation we just had.

Dr Joseph Shrager (Stanford, Calif). So, the point has been made several times, I think correctly, that the report does not really say anything about what used to be called pure bronchioloalveolar carcinoma. But, it does say something very strong, I think, about smaller invasive carcinomas or probably what most of us are seeing a lot of-which are these tumors that are sort of half groundglass and half invasive. The very strong statement that this report is saying about those tumors is that segmentectomy seems a lot better than wedge in that situation. Now, we do not know from your data, the fine points. You know, the Japanese say over and over that $50 \%$ is the cutoff point, that if it is less than $50 \%$ invasive, you can basically do a wedge, and if it is greater than 50\% solid on computed tomography, you cannot. You do not have that degree of fine hair-splitting here, but I think it is important to make that point - that segmentectomy is looking a lot better than wedge.

Dr Whitson. We tend to agree with you, Dr Shrager.

Dr Paul Schipper (Portland, Ore). Just a quick comment on what Doug said. I had the opportunity to read your report, and I think the methodology is very good, but that one input that you had, that kind of muddy definition of BAC makes the results something, maybe, that we cannot use. However, now we have this new definition of adenocarcinoma in situ and at some point, 5 years down the road, you are going to be able to take that one and plug it into this method. We do not have the opportunity of defining what tumors are going to do. They do what they do, and we sort of see what happens. I guess I would say that this study would need to be repeated with that carcinoma in situ population. Just to perhaps make an analogy, we operate on high-grade dysplasia, and that also is an in situ lesion, but we know a certain percentage of the time, it is not. I think it would be worth repeating this in a number of years looking at carcinoma in situ and not just depending on your pathologist saying this tumor does not look to be invasive and therefore it is not going to be in the lymph nodes. We need to see whether that is in fact the truth.

Dr Whitson. Very good point. Thank you, sir. 
TABLE E1. Lobectomy versus sublobar cohort demographics

\begin{tabular}{|c|c|c|c|}
\hline Variable & Lobectomy & Sublobar & $P$ value \\
\hline Patients (n) & 5532 & 1278 & \\
\hline Age (y) & & & .0005 \\
\hline$<40$ & 0.7 & 1.3 & \\
\hline $40-49$ & 5.0 & 4.4 & \\
\hline $50-59$ & 16.3 & 13.4 & \\
\hline $60-69$ & 32.3 & 29.7 & \\
\hline $70-79$ & 35.7 & 39.2 & \\
\hline$>80$ & 10.0 & 12.0 & \\
\hline Race & & & .0029 \\
\hline White & 83.7 & 83.6 & \\
\hline Black & 6.6 & 8.8 & \\
\hline Other & 9.7 & 7.6 & \\
\hline Gender & & & .56 \\
\hline Male & 37.7 & 36.9 & \\
\hline Female & 62.3 & 63.2 & \\
\hline Tumor size $(\mathrm{cm})$ & & & $<.0001$ \\
\hline$<2$ & 24.9 & 47.7 & \\
\hline $2-2.9$ & 32.1 & 29.7 & \\
\hline $3-3.9$ & 19.6 & 12.4 & \\
\hline $4-4.9$ & 8.9 & 4 & \\
\hline $5-5.9$ & 4.6 & 2.6 & \\
\hline $6-6.9$ & 3.0 & 1 & \\
\hline$\geq 7$ & 7 & 3.6 & \\
\hline Lymph nodes examined & & & $<.0001$ \\
\hline 0 & 8.4 & 61.9 & \\
\hline $1-10$ & 70.6 & 33.3 & \\
\hline $11-16$ & 13.6 & 3.4 & \\
\hline$\geq 17$ & 7.5 & 1.4 & \\
\hline Histologic type & & & .11 \\
\hline Not otherwise specified & 88.2 & 86.1 & \\
\hline Alveolar carcinoma & 1.0 & 1.0 & \\
\hline Nonmucinous & 4.4 & 6 & \\
\hline Mucinous & 5.5 & 6.3 & \\
\hline Mixed type & 0.9 & 0.6 & \\
\hline Grade & & & .041 \\
\hline Well differentiated & 45.6 & 48.3 & \\
\hline Moderately differentiated & 42.2 & 37.8 & \\
\hline Poorly differentiated & 11.5 & 12.7 & \\
\hline Undifferentiated & 0.6 & 1.2 & \\
\hline
\end{tabular}

Data presented as percentages. 